\title{
Tricyclic antidepressants and the incidence of certain cancers: a study using the GPRD
}

\begin{abstract}
AJ Walker*,1, T Card ${ }^{1,2,3}$, TE Bates ${ }^{4,5}$ and $K$ Muir $^{6}$
'Division of Epidemiology and Public Health, School of Community Health Sciences, University of Nottingham, Nottingham NG7 2UH, UK; ${ }^{2}$ Department of Gastroenterology, King's Mill Hospital, Mansfield Road, Sutton-in-Ashfield, Nottinghamshire, NG 17 4JL, UK; ${ }^{3}$ Nottingham Digestive Diseases Centre, NIHR Biomedical Research Unit, University of Nottingham, Nottingham NG7 2UH, UK; ${ }^{4}$ School of Natural and Applied Sciences, University of Lincoln, Brayford Pool, Lincoln LN6 7TS, UK; ${ }^{5}$ New-Use Therapeutics Limited, BioCity Nottingham, Pennyfoot Street, Nottingham NGI IGF, UK; ${ }^{6}$ Health Sciences Research Institute, Warwick Medical School, Warwick University, Coventry CV4 7AL, UK
\end{abstract}

BACKGROUND: Several studies suggest links between cancer and tricyclic antidepressant use.

METHODS: A case-control study using the General Practice Research Database examined whether previous tricyclic usage was associated with reduced incidence of brain (with glioma as a sub-category), breast, colorectal, lung and prostate cancers. Conditional logistic regression adjusted for age, gender, general practice, depression, smoking, body mass index, alcohol use and non-steroidal anti-inflammatory drug use.

RESULTS: A total of 31953 cancers were identified, each matched with up to two controls. We found a statistically significant reduction in tricyclic prescriptions compared with controls in glioma (odds ratio $(\mathrm{OR})=0.59,95 \%$ confidence interval $(\mathrm{Cl})=0.42-0.8 \mathrm{I})$ and colorectal cancer patients $(\mathrm{OR}=0.84, \mathrm{Cl}=0.75-0.94)$. These effects were dose-dependent ( $P$-values for trend, glioma $=0.0005$, colorectal $=0.00 \mathrm{I})$ and time-dependant $(P$-values for trend glioma $=0.0005$, colorectal $=0.0086)$. The effects were cancer-type specific, with lung, breast and prostate cancers largely unaffected by antidepressant use.

CONCLUSION: The biologically plausible, specific and dose- and time-dependant inverse association that we have found suggests that tricyclics may have potential for prevention of both colorectal cancer and glioma.

British Journal of Cancer (201 I) 104, 193-197. doi:I0.1038/sj.bjc.6605996 www.bjcancer.com

Published online 16 November 2010

(c) 20II Cancer Research UK

Keywords: tricyclic antidepressants; glioma; colorectal cancer; GPRD

Prevention of disease is better than its cure. In the case of cancer, where complete cure is often not possible, the strategies available for cancer prevention are still limited. However, the vast numbers of existing drugs used daily by millions of people are a potential source of agents that may help to prevent or even treat cancer. Despite notable examples of success such as the non-steroidal anti-inflammatory drugs (NSAIDs) (Cuzick et al, 2009) and statins (Kaye and Jick, 2004), few such agents have however yet been discovered.

Tricyclic antidepressants (TCAs) are widely prescribed for a variety of conditions, including depression, anxiety and insomnia. Although tricyclics have received some attention in epidemiological studies as possible carcinogens owing to their putative genotoxic activity (van Schaik and Graf, 1991), these have been inconclusive (Fulton-Kehoe et al, 2006; Xu et al, 2006; Tamim et al, 2007; Toh et al, 2007). There is substantial evidence that conflicts with this carcinogenic view of tricyclics, as particularly chlorimipramine (clomipramine), although also imipramine, citalopram,

\footnotetext{
*Correspondence: AJ Walker; E-mail: mcxajw2@nottingham.ac.uk

This study is based in part on data from the Full Feature General Practice Research Database obtained under licence from the UK Medicines and Healthcare Products Regulatory Agency. However, the interpretation and conclusions contained in this study are those of the authors alone. Received 7 June 2010; revised 4 October 2010; accepted 19 October 2010 ; published online 16 November 2010
}

amitriptyline and desipramine, have shown anticancer effects (Xia et al, 1999; Arimochi and Morita, 2006). Tricyclics have shown cytotoxic actions in various cancer cell lines including glioma cells (Xia et al, 1999; Daley et al, 2005; Levkovitz et al, 2005) and colorectal cancer cells (Arimochi and Morita, 2006), perhaps attributable to inhibition of mitochondrial complex III activity, leading to a decrease in mitochondrial membrane potential, and apoptosis (Weinbach et al, 1986; Daley et al, 2005). Animal studies substantiate an anticancer action in overcoming drug resistance in various cancer models, such as sarcoma, lymphocytic leukaemia and leukaemia grown as a solid tumour (Tsuruo et al, 1983; Merry et al, 1991; Pommerenke and Volm, 1995). Much attention has focussed on glioma as a target for tricyclics and there have been some preliminary clinical studies in humans using chlorimipramine therapeutically (Beaney et al, 2005).

Based upon their apparent sensitivity to tricyclics in vitro, we hypothesised that they would have a protective effect against glioma and colorectal cancer. We therefore conducted a case - control study using the GPRD to investigate this. In addition to examining these two tumour types, we also studied certain other cancers to look for specificity of any effect.

\section{MATERIALS AND METHODS}

A matched case-control study was used to investigate possible relations between drug usage and cancer incidence. Cases were 
defined as any person with a recorded diagnosis of brain tumour, breast, colorectal, lung or prostate cancer within the GPRD (diagnosis codes available on request); gliomas were considered separately. We excluded cases with $<5$ years of follow-up before the first recorded diagnosis of the relevant cancer, aged $<18$ years or with a diagnosis of any malignancy before the index cancer. Controls were individuals contributing data at the time of the case index date, with at least 5 years of follow-up before that date and with no recorded diagnosis of cancer. They were matched to cases by year of birth, gender and GP practice in a ratio of $2: 1$ where possible.

The GPRD is a prospectively gathered, anonymised database encompassing around 500 GP practices throughout the United Kingdom, and is the largest of its type in the world, with around 45 million patient-years of data spread across $\sim 6.5$ million patients. It provides data on patients including clinical diagnoses, treatments and outcomes. The database was established in 1987, with its development corresponding to the increased computerisation of GP practices, and its validity has been well documented ( Jick et al, 1991, 2003; Fombonne et al, 2004; Herrett et al, 2010).

The primary exposure was the use of any tricyclic antidepressant (section 4.3.3 of the British National Formulary (BNF)). We abstracted data on all such prescriptions at least 1 year before the date of diagnosis of the index cancer (or the equivalent pseudodiagnosis date of the cancer for controls). We first created a binary variable defining a tricyclic user as anyone with a repeat prescription for any tricyclic antidepressant, and comparing these with non-users. To allow assessment of dose response we determined the mean dose received across all exposed days for each patient. This was standardised across drug types by dividing by the maximum recommended doses for each drug (determined from the BNF). Each patient was then placed in a 'high dose', 'low dose' or 'unexposed' category, such that those exposed were divided equally into high- and low-dose categories. Length/ consistency of exposure was assessed by determining the number of days of exposure over a 10-year period before the index date. Any patient contributing data for less time was excluded for this part of the analysis. Exposed patients were then divided into two groups of equal size. In order to assess any potential confounding by indication, SSRI use was investigated by categorising those exposed to only SSRIs, only tricyclics, and both SSRIs and tricyclics. We extracted data on smoking status, body mass index (BMI), alcohol use, diagnosis of depression and prescriptions for NSAIDs and statins, which we considered as possible confounders.

\section{Statistical methods}

Data were analysed with conditional logistic regression, initially using univariate analysis, and then using a multivariate model. Results were presented as odds ratios (ORs), with $95 \%$ confidence intervals (CIs). Potential confounders were retained in the model if their inclusion produced a $10 \%$ variation in the measured size of effect. Analyses were performed on all cancer types together, followed by individual cancer types to look for specific effects. Trend was tested for by including dose/exposure duration in the conditional logistic regression model as a single, ordered categorical variable, with $P$-values obtained using the likelihoodratio test. All data handling and analysis was done using Stata v10.1 SE (Statacorp, College Station, TX, USA).

\section{RESULTS}

We identified 31953 cases with which 61591 controls were matched by age and gender. The cases consisted of 1372 cancers of the nervous system (of which 773 were gliomas), 10293 of the breast, 6232 colorectal, 6537 of the lung and 6537 of the prostate. Median age of patients across all cancer types was 68.2. Females made up 50.7\% (16212) of the study and had a median age of 65.6, and males had a median age of 70.9 . In all, $18.9 \%$ of cases and $17.6 \%$ of controls were exposed to one or more prescriptions for a tricyclic before one year before the index date. These data are summarised in Table 1.

As can be seen from Table 2, smoking was associated with an increased risk of cancer $(\mathrm{OR}=1.47, \mathrm{CI}=1.42-1.53)$, almost entirely attributable to lung cancer, with an OR of 7.4 $(\mathrm{CI}=6.74-8.12)$ in smokers compared with non-smokers. There is a slight increase in risk of cancer for alcohol users $(\mathrm{OR}=1.09$, $\mathrm{CI}=1.05-1.14)$, which was mostly because of breast $(\mathrm{OR}=1.11$, $\mathrm{CI}=1.04-1.18)$ and colorectal cancers $(\mathrm{OR}=1.12, \mathrm{CI}=1.02-$ 1.23). There is an apparent decrease in cancer risk as BMI increases, mainly found in lung cancer patients, where the decrease is caused by confounding by smoking status, and is not statistically significant if only non-smokers are considered. NSAID use is not significantly different for all cancers together, but shows a significant reduction in colorectal cancer $(\mathrm{OR}=0.93, \mathrm{CI}=0.87$ 0.99), as reported previously (Cuzick et al, 2009).

Analysis with tricyclic use coded as a binary variable (Table 3 ) demonstrates a significant reduction in tricyclic usage in colorectal cancer patients compared with controls (multivariate $\mathrm{OR}=0.84$,

Table I Characteristics

\begin{tabular}{|c|c|c|c|c|c|}
\hline \multirow[b]{2}{*}{ Cancer } & \multicolumn{2}{|c|}{ Cases } & \multicolumn{3}{|c|}{ Controls } \\
\hline & Number & $\%$ & & Number & $\%$ \\
\hline \multicolumn{6}{|l|}{ All } \\
\hline Total & 31953 & & & 61591 & \\
\hline Male & 15740 & 49.3 & & 29998 & 48.7 \\
\hline Female & 16212 & 50.7 & & 31593 & 51.3 \\
\hline Mean age & \multicolumn{5}{|c|}{68.3} \\
\hline \multicolumn{6}{|l|}{ Glioma } \\
\hline Total & 773 & & & 1502 & \\
\hline Male & 468 & 60.3 & & 906 & 60.5 \\
\hline Female & 305 & 39.7 & & 596 & 39.5 \\
\hline Mean age & \multicolumn{5}{|c|}{60.1} \\
\hline \multicolumn{6}{|l|}{ Colorectal } \\
\hline Total & 6232 & & & 12010 & \\
\hline Male & 3496 & 56.1 & & 6704 & 55.8 \\
\hline Female & 2736 & 43.9 & & 5306 & 44.2 \\
\hline Mean age & \multicolumn{5}{|c|}{70.9} \\
\hline \multicolumn{6}{|c|}{ Brain (excl glioma) } \\
\hline Total & 599 & & & 1164 & \\
\hline Male & 214 & 35.7 & & 413 & 35.5 \\
\hline Female & 385 & 64.3 & & 751 & 64.5 \\
\hline Mean age & \multicolumn{5}{|c|}{65.8} \\
\hline \multicolumn{6}{|l|}{ Breast } \\
\hline Total & 10293 & & & 20096 & \\
\hline Male & - & - & & - & - \\
\hline Female & 10293 & 100.0 & & 20096 & 100.0 \\
\hline Mean age & \multicolumn{5}{|c|}{62.5} \\
\hline \multicolumn{6}{|l|}{ Lung } \\
\hline Total & 6537 & & & 12514 & \\
\hline Male & 4035 & 61.73 & & 7653 & 61.16 \\
\hline Female & 2502 & 38.27 & & 4861 & 38.84 \\
\hline Mean age & \multicolumn{5}{|c|}{71.0} \\
\hline \multicolumn{6}{|l|}{ Prostate } \\
\hline Total & 7531 & & & 14329 & \\
\hline Male & 7531 & 100.0 & & 14329 & 100.0 \\
\hline Female & - & - & & - & - \\
\hline Mean age & \multicolumn{5}{|c|}{72.5} \\
\hline
\end{tabular}

A summary of the characteristics of the population, including for each of the cancers. 
Table 2 Covariates

\begin{tabular}{|c|c|c|c|c|c|c|}
\hline Exposure & Status & Case & Control & OR & $95 \%$ & $\mathbf{C l}$ \\
\hline \multirow[t]{4}{*}{ Smoking status } & No & 15369 & 32153 & I & & \\
\hline & Ex & 5911 & 10263 & 1.23 & 1.19 & 1.28 \\
\hline & Yes & 7978 & 11615 & 1.47 & 1.42 & 1.53 \\
\hline & Missing & 2695 & 7560 & 0.69 & 0.65 & 0.72 \\
\hline \multirow[t]{4}{*}{ Alcohol use } & No & 4778 & 9542 & I & & \\
\hline & Ex & 348 & 572 & 1.24 & 1.08 & 1.43 \\
\hline & Yes & 21028 & 38670 & 1.09 & 1.05 & 1.14 \\
\hline & Missing & 5799 & 12807 & 0.87 & 0.83 & 0.91 \\
\hline \multirow[t]{6}{*}{ Mean BMI } & Normal & 10713 & 19466 & । & & \\
\hline & Underweight & 701 & 1020 & 1.26 & 1.14 & 1.39 \\
\hline & Overweight & 10086 & 19005 & 0.96 & 0.93 & 1.00 \\
\hline & Obese & 3191 & 6240 & 0.93 & 0.89 & 0.98 \\
\hline & Morbidly obese & 961 & 2008 & 0.88 & 0.81 & 0.95 \\
\hline & Missing & 6301 & 13852 & 0.79 & 0.76 & 0.82 \\
\hline \multirow[t]{2}{*}{ NSAID use } & No & 21122 & 41006 & । & & \\
\hline & Yes & 10831 & 20585 & 1.02 & 0.99 & 1.05 \\
\hline \multirow[t]{2}{*}{ Statin use } & No & 26957 & 51933 & 1 & & \\
\hline & Yes & 4996 & 9658 & 1.00 & 0.96 & 1.04 \\
\hline \multirow[t]{2}{*}{ Depression } & No & 23890 & 47458 & 1 & & \\
\hline & Yes & 8063 & 14133 & 1.15 & 1.11 & 1.19 \\
\hline
\end{tabular}

Abbreviations: $\mathrm{Ex}=$ former smoker; NSAID $=$ non-steroidal anti-inflammatory drug; $\mathrm{BMI}=$ body mass index; $\mathrm{OR}=$ odds ratio; $\mathrm{Cl}=$ confidence interval. Changes in cancer risk for each of the covariates. These results are for all the studied cancer types grouped together, and hence do not describe differences in exposures between cancer type (see text).

Table 3 Binary analysis

\begin{tabular}{|c|c|c|c|c|c|c|c|c|c|}
\hline \multirow[b]{2}{*}{ Cancer type } & \multirow[b]{2}{*}{ Exposed } & \multirow[b]{2}{*}{ Case } & \multirow[b]{2}{*}{ Control } & \multicolumn{3}{|c|}{ Univariate } & \multicolumn{3}{|c|}{ Multivariate* } \\
\hline & & & & OR & $95 \%$ & Cl & OR & $95 \%$ & $\mathrm{Cl}$ \\
\hline \multirow[t]{2}{*}{ Glioma } & No & 706 & 1317 & I & & & I & & \\
\hline & Yes & 67 & 185 & 0.66 & 0.49 & 0.89 & 0.59 & 0.42 & 0.81 \\
\hline \multirow[t]{2}{*}{ Colorectal } & No & 5574 & 10543 & I & & & 1 & & \\
\hline & Yes & 658 & 1467 & 0.85 & 0.77 & 0.94 & 0.84 & 0.75 & 0.94 \\
\hline Brain & No & 505 & 1013 & I & & & 1 & & \\
\hline (excl glioma) & Yes & 94 & $15 \mid$ & 1.26 & 0.95 & 1.67 & 1.00 & 0.72 & 1.38 \\
\hline \multirow[t]{2}{*}{ Breast } & No & 8651 & 16834 & I & & & 1 & & \\
\hline & Yes & 1642 & 3262 & 0.98 & 0.92 & 1.05 & 0.97 & 0.91 & 1.04 \\
\hline \multirow[t]{2}{*}{ Lung } & No & 5555 & 10992 & I & & & 1 & & \\
\hline & Yes & 982 & 1522 & 1.30 & 1.19 & 1.42 & 1.14 & 1.02 & 1.28 \\
\hline \multirow[t]{2}{*}{ Prostate } & No & 6861 & 13112 & 1 & & & 1 & & \\
\hline & Yes & 670 & 1217 & 1.06 & 0.96 & 1.17 & 0.94 & 0.84 & 1.04 \\
\hline \multirow[t]{2}{*}{ All } & No & 27841 & 53790 & I & & & I & & \\
\hline & Yes & 4112 & 7801 & 1.03 & 0.99 & 1.07 & 0.93 & 0.89 & 0.97 \\
\hline
\end{tabular}

Abbreviations: $\mathrm{OR}=$ odds ratio; $\mathrm{Cl}=$ confidence interval. Patients with repeat prescriptions for tricyclics were defined as exposed. *Corrected for smoking status, diagnosis of depression, alcohol use and BMI. NSAID use corrected for in colorectal cancer only.

$\mathrm{CI}=0.75-0.94)$. Tricyclic use is also significantly lower in glioma patients compared with controls, with a larger effect estimate $(\mathrm{OR}=0.59, \mathrm{CI}=0.42-0.81)$. For most cancers, we found little evidence of confounding by the available potential confounders, except for lung cancer, where smoking status had a large confounding effect. The significant increase in tricyclic use observed in the univariate model $(\mathrm{OR}=1.30, \mathrm{CI}=1.19-1.42)$ is greatly reduced when adjusted for confounders $(\mathrm{OR}=1.14$, $\mathrm{CI}=1.02-1.28)$. Other cancers show little variation in tricyclic usage, with ORs very close to one.

For glioma, selective serotonin reuptake inhibitor (SSRI) use without tricyclic use showed little deviation between cases and controls $(\mathrm{OR}=0.96, \mathrm{CI}=0.61-1.53)$. This is in contrast to tricyclic
Table 4 Dose and duration

\begin{tabular}{|c|c|c|c|c|c|c|c|}
\hline Cancer & $\begin{array}{l}\text { Exposure } \\
\text { status }\end{array}$ & Case & Control & OR & $95 \%$ & Cl & $P$-trend \\
\hline \multicolumn{8}{|l|}{ Dose } \\
\hline \multirow[t]{3}{*}{ Glioma } & Unexposed & 707 & 1323 & । & & & \\
\hline & Low dose & 38 & 97 & 0.67 & 0.45 & 1.01 & \\
\hline & High dose & 28 & 82 & 0.49 & 0.30 & 0.78 & 0.0005 \\
\hline \multirow[t]{3}{*}{ Colorectal } & Unexposed & 5592 & 10595 & I & & & \\
\hline & Low & 382 & 821 & 0.87 & 0.76 & 1.00 & \\
\hline & High & 258 & 594 & 0.79 & 0.67 & 0.93 & 0.0010 \\
\hline \multicolumn{8}{|l|}{ Duration (days) } \\
\hline \multirow[t]{3}{*}{ Glioma } & Unexposed & 399 & $105 \mid$ & । & & & \\
\hline & $1-117$ & 22 & 71 & 0.65 & 0.37 & 1.13 & \\
\hline & $>117$ & 14 & 75 & 0.36 & 0.19 & 0.69 & 0.0005 \\
\hline \multirow[t]{3}{*}{ Colorectal } & Unexposed & 3598 & 7752 & I & & & \\
\hline & $1-117$ & 345 & 747 & 0.84 & 0.70 & 1.01 & \\
\hline & $>117$ & 305 & 785 & 0.82 & 0.68 & 0.97 & 0.0086 \\
\hline
\end{tabular}

Abbreviations: $\mathrm{OR}=$ odds ratio; $\mathrm{Cl}=$ confidence interval. Glioma and colorectal cancer dose-response and duration results. Other cancer types did not show consistent dose-response relationships. All analyses in this table are corrected for smoking status, diagnosis of depression, alcohol use and BMI. NSAID use corrected for in colorectal cancer only.

use with $(\mathrm{OR}=0.50, \mathrm{CI}=0.27-0.92)$ and without $(\mathrm{OR}=0.74$, $\mathrm{CI}=0.52-1.06)$ SSRI use. Colorectal cancer was similar to glioma in terms of exclusive SSRI use $(\mathrm{OR}=0.95, \mathrm{CI}=0.81-1.12)$, and showed a similar pattern to the above binary analysis for tricyclic use with SSRI use $(\mathrm{OR}=0.85, \mathrm{CI}=0.70-1.02)$ and exclusive tricyclic use $(\mathrm{OR}=0.85, \mathrm{CI}=0.76-0.95)$.

When divided into 'low' and 'high' dose exposure (Table 4), tricyclic use is significantly lower at high doses for both glioma $(\mathrm{OR}=0.49, \mathrm{CI}=0.30-0.78)$ and colorectal cancer $(\mathrm{OR}=0.79$, $\mathrm{CI}=0.67-0.93)$. Highly significant trends validate these findings further for glioma $(P=0.0005)$ and colorectal cancer $(P=0.0010)$. Other cancer types were considered in the same way, although no notable or statistically significant trends were present (data not shown). We then investigated relationships with duration of tricyclic exposure. As with the dose analysis, long-term use is significantly lower in glioma $(\mathrm{OR}=0.36, \mathrm{CI}=0.19-0.69)$ and colorectal cancer $(\mathrm{OR}=0.82, \mathrm{CI}=0.68-0.97)$. Highly significant trends were observed again for glioma $(P=0.0005)$ and colorectal cancer $(P=0.0086)$. No notable or statistically significant trends were present for other cancers (data not shown).

\section{DISCUSSION}

This study finds that tricyclic use may be associated with a subsequent reduction in the risk of glioma and colorectal cancer. These protective effects appear to be specific to these particular cancers, as it was not observed for the other cancers studied, although we cannot rule out a protective effect in cancers not covered. The data also indicate that these apparent protective effects are greatest for patients receiving high-dose prescriptions over a long period.

Our data have certain important strengths. Our use of routinely collected general practice records (from the GPRD) ensured that there was no opportunity for recall bias to effect the ascertainment of exposures. In addition, by selecting all relevant malignancies within the population and a random sample of the suitable controls, we eliminated the possibility of selection bias. However, our data selection does have some weaknesses. Although the numerous validation studies of various diagnoses suggest that our outcomes were accurately coded, as the electronic recording of prescription data does for our primary exposure, we cannot be equally confident about the recording of all potential confounders. As Table 2 shows, there are much missing data with respect to 
smoking, obesity and alcohol, and therefore a potential for residual confounding by these factors. However, we believe that except for lung cancer where this is clearly an issue (and residual confounding by smoking might account for the positive association with tricyclics), the near total lack of confounding detected argues that any such residual will be minor. A potentially greater issue is that we lack any data on other potential confounders such as diet and exercise, and hence their impact on the results cannot be assessed.

Another strength of our study is that by studying several cancers, we have demonstrated that the protective effect of tricyclics appears to be specific to certain malignancies. Because of the study size, we have also been able to demonstrate that longer-term use and higher doses of tricyclics appear to give greater protection from glioma and colorectal cancers. As the proposed anticancer mechanism of action is a mitochondrial one (Daley et al, 2005) and independent of the psychoactive mechanism of action, there is reason to believe that these findings are generalisable, and not restricted only to a 'depressed' population.

Confounding by indication is important and if SSRIs are considered as were tricyclics, their pattern is similar (data not shown), possibly because their use is predictive of tricyclic use. If patients using SSRIs exclusively (i.e., no tricyclics) are considered, most of the effect disappears. The multivariate results were adjusted for diagnosis of depression, and this adjustment increased the apparent protective effect of tricyclics. It would seem more biologically plausible for depression to increase cancer risk than decrease it, and it is therefore likely that depression is a proxy for high-dose tricyclics (as it is usually treated with a higher dose than other indications, such as pain). This is supported by the relation with dose (where those without depression have a higher proportion of low dose and vice versa).

Previous studies have examined tricyclics and the incidence of colorectal (Xu et al, 2006), prostate (Tamim et al, 2007), breast (Cotterchio et al, 2000; Gonzalez-Perez and Garcia Rodriguez, 2005; Fulton-Kehoe et al, 2006; Wernli et al, 2009) and lung cancers (Toh et al, 2007), but have shown little consistency, and significant evidence has been found to link tricyclics with cancer. A study on colorectal cancer (Xu et al, 2006) hypothesised that tricyclics are genotoxic, and therefore increase cancer risk, but, their results suggest a nonsignificant protective effect, as did another recent study (Patricia et al, 2009). Our findings for colorectal cancer fit well with these data, the statistically significant protection being a function of our greater numbers. The previous lung cancer study (Toh et al, 2007) showed an apparent increase in risk with tricyclic use, which is largely mitigated by adjusting for confounders (including smoking status), as with our data.

We have found a significant reduction in incidence of colorectal cancer and glioma, consistent with previous laboratory evidence (Daley et al, 2005), and not inconsistent with other epidemiological studies. The findings show specificity of protection for those malignancies originally hypothesised and show a dose-response and a clear temporal relationship. It is credible that our associations may be causal, although the modest size of the effect limits the potential of these drugs as a chemopreventative agent in the general population. As glioma is a rare cancer with ill-defined high-risk groups, prescribing chemopreventative drugs are of limited value in the general population; thus, we estimate that $\sim 60000$ people would need to be treated (for $>117$ days) in order to prevent one glioma. Groups at increased risk of colorectal cancer (e.g., those with a familial or other genetic predisposition) might still represent an appropriate group for an RCT as they would have the best chance of benefiting from chemoprevention, here although one would need to balance potential benefits against possible side effects.

If the antineoplastic effects of tricyclics are to be therapeutically useful, it is likely to follow identification of a potent compound within the group, or in postdiagnosis treatment of colorectal cancer and glioma. Thus, aspirin, a recognised prophylactic for colorectal cancer, has recently been found to reduce colorectal cancer mortality when used after diagnosis (Chan et al, 2009; Zell et al, 2009), and to an extent achieved previously only by far more toxic compounds. It would therefore be useful to determine whether tricyclics have similar effects on colorectal cancer and glioma.

\section{Conflict of interest}

AJW is funded by a MRC DTA studentship, the MRC provided access to the GPRD database through its licence agreement with MHRA, and the spouse of TRC is an employee of Astra Zeneca.

\section{Author contributions}

TEB and KM were involved with the conception of the project and acquisition of funding, and in collaboration with AJW participated in study design. Analysis was carried out by AJW and TRC. AJW wrote the first draft under the supervision of TRC, and all authors contributed to subsequent drafting.

\section{REFERENCES}

Arimochi H, Morita K (2006) Characterization of cytotoxic actions of tricyclic antidepressants on human HT29 colon carcinoma cells. Eur J Pharmacol 541: $17-23$

Beaney RP, Gullan RW, Pilkington GJ (2005) Therapeutic potential of antidepressants in malignant glioma: clinical experience with clomipramine. J Clin Oncol (Meeting Abstracts) 23: 1535

Chan AT, Ogino S, Fuchs CS (2009) Aspirin use and survival after diagnosis of colorectal cancer. JAMA 302: 649-658

Cotterchio M, Kreiger N, Darlington G, Steingart A (2000) Antidepressant medication use and breast cancer risk. Am J Epidemiol 151: 951 - 957

Cuzick J, Otto F, Baron JA, Brown PH, Burn J, Greenwald P, Jankowski J, La Vecchia C, Meyskens F, Senn HJ, Thun M, Cuzick J, Otto F, Baron JA, Brown PH, Burn J, Greenwald P, Jankowski J, La Vecchia C, Meyskens F, Senn HJ, Thun M (2009) Aspirin and non-steroidal anti-inflammatory drugs for cancer prevention: an international consensus statement. Lancet Oncol 10: $501-507$

Daley E, Wilkie D, Loesch A, Hargreaves IP, Kendall DA, Pilkington GJ, Bates TE, Daley E, Wilkie D, Loesch A, Hargreaves IP, Kendall DA, Pilkington GJ, Bates TE (2005) Chlorimipramine: a novel anticancer agent with a mitochondrial target. Biochem Biophys Res Commun 328: 623-632
Fombonne E, Heavey L, Smeeth L, Rodrigues LC, Cook C, Smith PG, Meng L, Hall AJ, Fombonne E, Heavey L, Smeeth L, Rodrigues LC, Cook C, Smith PG, Meng L, Hall AJ (2004) Validation of the diagnosis of autism in general practitioner records. BMC Public Health 4: 5

Fulton-Kehoe D, Rossing MA, Rutter C, Mandelson MT, Weiss NS (2006) Use of antidepressant medications in relation to the incidence of breast cancer. Br J Cancer 94: $1071-1078$

Gonzalez-Perez A, Garcia Rodriguez LA (2005) Breast cancer risk among users of antidepressant medications. Epidemiology 16: $101-105$

Herrett E, Thomas SL, Schoonen WM, Smeeth L, Hall AJ (2010) Validation and validity of diagnoses in the General Practice Research Database: a systematic review. Br J Clin Pharmacol 69: 4-14

Jick H, Jick SS, Derby LE (1991) Validation of information recorded on general practitioner based computerised data resource in the United Kingdom. BMJ 302: $766-768$

Jick SS, Kaye JA, Vasilakis-Scaramozza C, Garcia Rodriguez LA, Ruigomez A, Meier CR, Schlienger RG, Black C, Jick H, Jick SS, Kaye JA, VasilakisScaramozza C, Garcia Rodriguez LA, Ruigomez A, Meier CR, Schlienger RG, Black C, Jick H (2003) Validity of the general practice research database. Pharmacotherapy 23: 686-689 
Kaye JA, Jick H (2004) Statin use and cancer risk in the General Practice Research Database. Br J Cancer 90: 635-637

Levkovitz Y, Gil-Ad I, Zeldich E, Dayag M, Weizman A (2005) Differential induction of apoptosis by antidepressants in glioma and neuroblastoma cell lines: evidence for p-c-Jun, cytochrome $c$, and caspase-3 involvement. J Mol Neurosci 27: 29-42

Merry S, Hamilton TG, Flanigan P, Freshney RI, Kaye SB (1991) Circumvention of pleiotropic drug resistance in subcutaneous tumours in vivo with verapamil and clomipramine. Eur J Cancer 27: $31-34$

Patricia FC, Brian LS, Lynn R (2009) Antidepressant use and colorectal cancer risk. Pharmacoepidemiol Drug Saf 18: 1111 -1114

Pommerenke EW, Volm M (1995) Reversal of doxorubicin-resistance in solid tumors by clomipramine. In Vivo 9: 99-101

Tamim HM, Mahmud S, Hanley JA, Boivin JF, Stang MR, Collet JP (2007) Antidepressants and risk of prostate cancer: a nested case-control study. Prostate Cancer Prostatic Dis 11: 53-60

Toh S, García Rodríguez L, Hernández-Díaz S (2007) Use of antidepressants and risk of lung cancer. Cancer Causes and Control 18: $1055-1064$

Tsuruo T, Iida H, Nojiri M, Tsukagoshi S, Sakurai Y (1983) Potentiation of chemotherapeutic effect of vincristine in vincristine resistant tumor bearing mice by calmodulin inhibitor clomipramine. J Pharmacobiodyn 6: $145-147$

van Schaik N, Graf U (1991) Genotoxicity evaluation of five tricyclic antidepressants in the wing somatic mutation and recombination test in Drosophila melanogaster. Mutat Res 260: 99-104

Weinbach EC, Costa JL, Nelson BD, Claggett CE, Hundal T, Bradley D, Morris SJ (1986) Effects of tricyclic antidepressant drugs on energylinked reactions in mitochondria. Biochem Pharmacol 35: 1445-1451

Wernli KJ, Hampton JM, Trentham-Dietz A, Newcomb PA (2009) Antidepressant medication use and breast cancer risk. Pharmacoepidemiol Drug Saf 18: 284-290

Xia Z, Bergstrand A, DePierre JW, Nassberger L (1999) The antidepressants imipramine, clomipramine, and citalopram induce apoptosis in human acute myeloid leukemia HL-60 cells via caspase-3 activation. J Biochem Mol Toxicol 13: $338-347$

Xu W, Tamim H, Shapiro S, Stang MR, Collet J-P (2006) Use of antidepressants and risk of colorectal cancer: a nested case-control study.[see comment]. Lancet Oncol 7: 301-308

Zell JA, Ziogas A, Bernstein L, Clarke CA, Deapen D, Largent JA, Neuhausen SL, Stram DO, Ursin G, Anton-Culver H (2009) Nonsteroidal anti-inflammatory drugs: effects on mortality after colorectal cancer diagnosis. Cancer 115: $5662-5671$ 